\title{
Population structure and habitat use of gelada baboon (Theropithecus gelada) in Wof-Washa Forest (Gosh-Meda Area), Central Ethiopia
}

\author{
Birhanu Goshme ${ }^{1}$ and Mesele Yihune $2^{2^{*}}$
}

\begin{abstract}
Background: Gelada baboon is one of the endemic mammals of Ethiopia residing in different highlands. The population structure and habitat use of gelada baboon in Wof-Washa particularly Gosh Meda area was investigated from September 2016 to August 2017. Total counting method was used to collect data on the population status by dividing the study area in to four blocks, namely, Kundi, Arbgebeya, Goshber, and Goshmeda. Data were analyzed using SPSS software. The age-sex category and the numbers of geladas found within the different blocks were analyzed using one-way ANOVA, and paired $t$ test was also used to analyze the pair wise comparison of the different age and sex categories during both dry and wet seasons.

Results: A total of 435 and 471 gelada baboons were counted during the wet and dry seasons, respectively. The maximum group size consisted of 178 individuals whereas the minimum group size contained 53 individuals. Out of the total population adult females accounted for $54.7 \%$ in the wet and $54.56 \%$ in the dry seasons. There was a significant difference among the age-sex categories in both the wet $\left(F_{2} 432=630, P<0.05\right)$ and dry $\left(F_{2468}=696.6\right.$, $P<0.05)$ seasons. The male to female ratio was 1:5.7 during wet season and 1:5.8 during dry season. So that the population will have a better chance to increase in the study area.

Conclusion: Wof-Washa Forest could be a good site for eco-tourism activities due to the presence of endemic animals and its scenic beauty. However, the quality of the habitat is decreasing due to livestock grazing, agricultural expansion, and invasion of exotic plants species. Therefore, appropriate conservation measures should be implemented to conserve gelada baboon in particular and other wildlife resources in general.
\end{abstract}

Keywords: Age structure, Gelada baboon, Habitat association, Population status, Sex ratio, Wof-Washa Forest

\section{Background}

Gelada baboons (Theropithecus gelada) are one of the endemic species of Ethiopia (Dessalegn and Afework 2014) and the only extant genus Theropithecus (Dunbar 1998). Geographically, they are confined to the elevation of montane grassland of Ethiopia (Habtamu and Subramanian 2013). The central and the northern highlands of Ethiopia are the well-known dwelling places for them. Moreover, another different population of gelada is found in south of

\footnotetext{
* Correspondence: mesyih@gmail.com

${ }^{2}$ Department of Zoological Sciences, Addis Ababa University, P.O.Box 1176,

Addis Ababa, Ethiopia

Full list of author information is available at the end of the article
}

the Rift Valley in Arsi (Mori and Belay, 1990). The areas preferred by geladas to live are highlands that are commonly cooler and less arid than lowlands. This makes geladas be less exposed to the negative effect of dry season in terms of food availability (Habtamu and Subramanian 2013). The rocky cliffs where geladas spend the night time provide protection from predators while the grasslands around them serve as foraging areas (Dunbar 1977).

Gelada baboons are covered with dark brown hair. They have a face with pale eyelids, arms and feet which are black, a shorter tail compared to their body which contains a branch of hair at the end. The back side of the male geladas contains a long heavy cape of hair

(c) The Author(s). 2018 Open Access This article is distributed under the terms of the Creative Commons Attribution 4.0 International License (http://creativecommons.org/licenses/by/4.0/), which permits unrestricted use, distribution, and reproduction in any medium, provided you give appropriate credit to the original author(s) and the source, provide a link to the Creative Commons license, and indicate if changes were made. The Creative Commons Public Domain Dedication waiver (http://creativecommons.org/publicdomain/zero/1.0/) applies to the data made available in this article, unless otherwise stated. 
(Habtamu and Subramanian 2013). Geladas are distinguished from other baboons in that they have shorter jaws, longer face, a bulging cheek, and a snub snout which is alike to the snout of chimpanzee (Radek et al. 2014). The bright red patch on the chest of geladas makes them distinguished and called as bleeding heart baboons. The presence of a greater degree of sexual dimorphism in which males are larger than females is the other distinguishing feature of the extant genus Theropithecus (Iwamoto 1993) (Fig. 1).

Geladas have social system which is greatly complex, with a strong female instinct and a stable, maternally inherited dominant hierarchy (Radek et al. 2014). Those females in one-male unit are believed to have more close relations to each other (Eshetu and Balakrishnan 2015). There are three levels of organizations in the social structures of geladas. Out of these levels, primary level of organization is the commonest one. It contains one-male unit in which the reproductive male is the leader, $1-12$ reproductive females, 1 or more follower males and their dependent offspring, and all-male unit which contains 2-15 young adults and sub-adult males. The band which is composed of the multiple unit and all-male units having members that sleep and forage together is the second level of organization (Snyder-Mackler et al. 2012). The band consists of 30 to 270 individuals that is, about 10 reproductive units and 1 all-male unit. The one-male unit is the reproductive and social unit in gelada society while the band is the ecological and genetic unit and the herd is the foraging unit. The reproductive and the all-male groups share a common home range (Dunbar 1986). The herd consists of 260 reproductive units sometimes which are from different bands that overlap extensively (Crook 1966; Dunbar 1986).

Larger number of gelada baboons is found in the Simien Mountains National Park (Beehner et al. 2008). Those that are found in protected areas are well studied. However, the gelada baboons in Wof-Washa (Gosh Meda) have not been considered. Due to this reason, no comprehensive population estimate was carried out and no information is found to compare the number of geladas with those that live in other protected areas. Therefore, studying the population status and habitat use of geladas in Wof-Washa particularly in Gosh-Meda gives first-hand information for concerned bodies. Hence, the purpose of this study is to estimate the population structure and identify habitat use of gelada baboon in Wof-Washa Forest (Gosh Meda), Central Ethiopia.

\section{Methods}

\section{Study site}

Wof-Washa Forest is located in the central highlands of Ethiopia in Amhara Region North Shoa Zone. It is found between Ankober, Tarmaber, and Basona Worana districts (Eyosias and Teshome 2015). It is situated at a distance of $30 \mathrm{~km}$ and $160 \mathrm{~km}$ from Debre Berhan and Addis Ababa, respectively (Demel and Tamrat 1995). It is situated between $9^{\circ} 44^{\prime}$ and $9^{\circ} 46^{\prime} \mathrm{N}$ latitude and $39^{\circ} 44^{\prime}$ and $39^{\circ} 47^{\prime} \mathrm{E}$ longitude. The area coverage of the forest is about $82 \mathrm{~km}^{2}$ (Brnesh et al. 2015) (Fig. 2).

The altitude of the area ranges from 2000 to 3730 m.a.s.l. Its topography is characterized by extremely steep slopes whereby the forest is located on the east side of the mountains (Eyosias and Teshome 2015). The area is also found on the division site forming the base for the Blue Nile and Awash rivers. Hence, Wof-Washa is the best

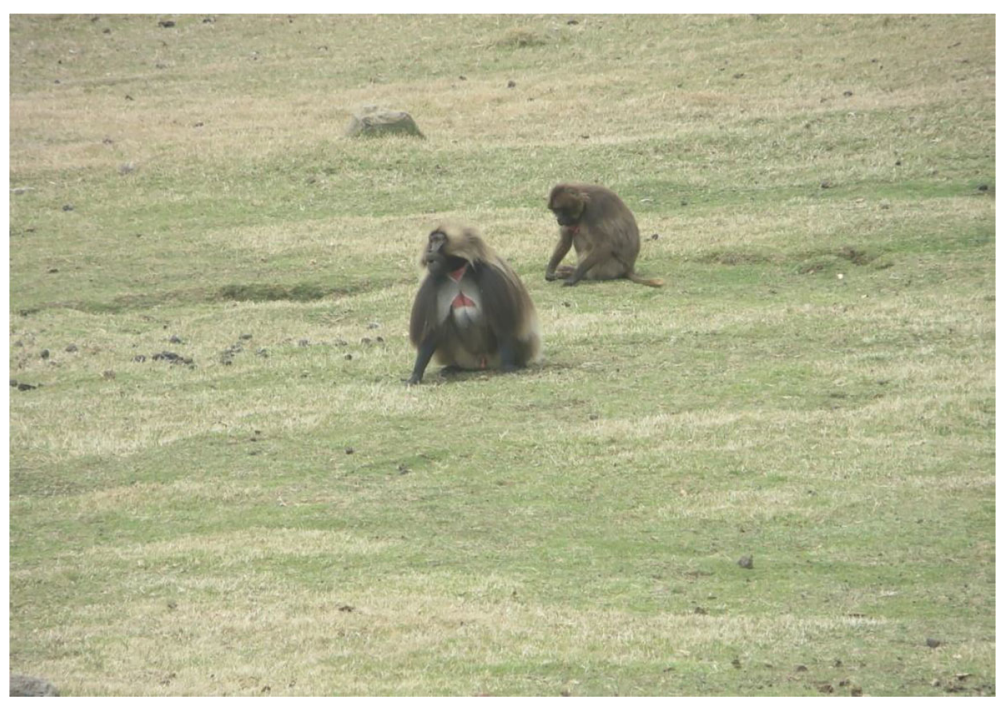

Fig. 1 Adult male and female gelada baboon 


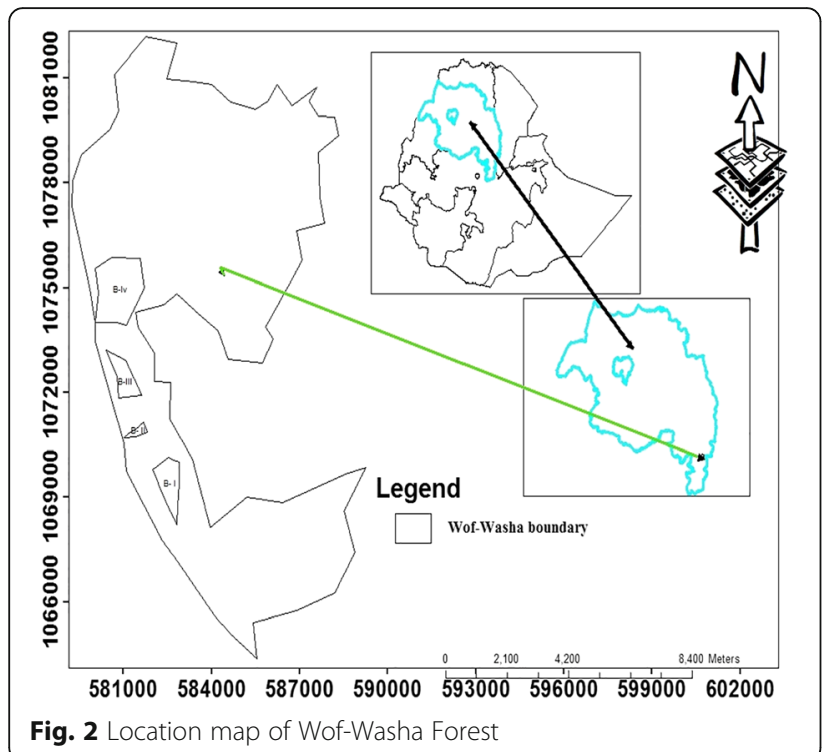

water catchment area as it contains more than seven streams that flow to Awadi which is the main tributary of Awash (Demel and Tamrat 1995). The soil type is black and compact clay soil on the flat highlands and bottom of wide valleys whereas on the mountain and valley slopes and on better drained highlands is reddish-brown and heavy loam soil (Demel and Tamrat 1995).

The mean annual rainfall is $1400 \mathrm{~mm}$, and it has a bimodal type of distribution having a long wet season (from July to September). On the other hand, Wof-Washa has a mean annual temperature with a minimum of $10^{\circ} \mathrm{C}$ and a maximum of $20^{\circ} \mathrm{C}$. However, the range lies between $-5^{\circ} \mathrm{C}$ and $35^{\circ} \mathrm{C}$ (Brnesh et al. 2015).

Wof-Washa Forest is characterized by dry montane mixed broad leaved and conifer forest (EWNHS 2010). It can be categorized into three zones described as the upper Afromontane Erica arborea which includes tree heath (Erica arborea), Curry bush (Hypericum revolutum), Lobelia (Lobelia spp.), dominant woody trees which include African pencil cedar (Juniperus procera), Yellow wood (Podocarpus falcatus), Olive (Olea europaea subsp.), plains muhly (cuspidata), Hagenia (Hagenia abyssinica), and Forest velvet false-currant (Allophylus abyssinica) and Wild olive (Olea africana) which is dominant species in the southern part of the forest being separated by farm lands (Demel and Tamrat 1995).

Mammals like Menelik's bushbuck (Tragelaphus scriptus meneliki), Colobus monkey (Colobus gureza), duiker (Sylvicapra grimmia), gelada baboon (Theropithecus gelada), grivet (Chlorocebus aethiops), European hare (Lepus europaes), spotted hyena (Crocuta crocuta), African wild dog (Lycaon pictus), rock hyrax (Procavia capensis), golden jackal (Canis aureus), klipspringer (Oreotragus oreotragus), leopard (Pantra pardus), Olive baboon (Papio anubis), porcupine (Histrix cristata), wild cat (Felis silvestris), and different rodent species are found (Demel and Tamrat 1995). Bird species like francolin (Francolinus pondicerianus), guinea fowl (Numida maleagris) (Demel and Tamrat, 1995), and other highland birds including the endemic Ankober serin (Serinus striolatus) are also found (EWNHS 2010).

\section{Data collection \\ Population count}

The study was carried out from September 2016 to August 2017. Total count method was used to count the population of gelada in the study area. Total count is the most effective method to determine the population size of geladas as they live in open habitats that facilitate visibility and are highly mobile. Therefore, the suitability of the habitat to observe, the high mobility, the audibility of detectable cues, and the variability of group size across time of gelada baboons make total count method as the most effective technique (Beehner et al. 2008).

To count the population of gelada baboons, people were trained and assigned in each block. For each counting block, two trained guards were assigned in order to make more reliable and counting was carried out at the same time to avoid double counting. The time for counting was suitable from 8:00 to 12:00 in the morning shift during both the wet and dry seasons. The age and sex categorization was done based on the physical appearance of gelada baboons. Adult males are distinguished from others by their manes and about twice body size compared to adult females and sub-adult males. Adult females are different from sub-adult females by their larger size and again differ from sub-adult males in that the sub-adult males begin to grow manes. If the geladas were out of the above four categories, they were categorized as juveniles (Beehner et al. 2008). The mean group size of bands, OMUs, AMGs, and composition of OMU and AMG was also recorded. During data collection, the habitat type also recoded.

\section{Data analysis}

Data was analyzed using SPSS version 20.0 computer software. The population status at different age and sex groups during both seasons was analyzed using one-way ANOVA. Paired $t$ test was used to compare the number of individuals in different age and sex groups.

\section{Results}

\section{Population estimate}

The total number of gelada baboons recorded during the wet season was 435 , and the dry season was 471 (Table 1). The average number of gelada baboons during the study period was 453 . There was no a significant 
Table 1 Number of gelada baboon recorded during wet and dry seasons

\begin{tabular}{llllll}
\hline Seasons & Block-1 & Block-2 & Block-3 & Block-4 & Total \\
\hline Wet & 80 & 53 & 129 & 173 & 435 \\
Dry & 107 & 54 & 132 & 178 & 471 \\
Mean & 93.5 & 53.5 & 130.5 & 175.5 & 453 \\
\hline
\end{tabular}

difference in the number of individuals recorded during the wet and dry seasons $(\chi 2=2.6, \mathrm{df}=3, P>0.05)$.

Gelada baboons were observed in different habitat type of the study area. A total of 403 and 389 individuals were counted from the open grassland during the dry and wet seasons, respectively. On the other hand, the least (12) recorded was from plantation forest during both seasons (Table 2). The distribution of gelada baboons in the three habitat types showed a slight variation between wet and dry seasons. However, this variation was not statistically significant $\left(\chi^{2}=4.2, \mathrm{df}=2\right.$, $P>0.05)$.

\section{Age and sex structure}

There was no statistically significant difference among the various age and sex groups of gelada baboons counted during wet and dry season $\left(\chi^{2}=0.04, \mathrm{df}=4\right.$, $P<0.05$ ) (Table 3).

The age and sex of the total population included $8.97 \%$ adult males, $54.7 \%$ adult females, $3.45 \%$ sub-adult males, $16.1 \%$ sub-adult females, and $16.78 \%$ unidentified sex juveniles. There was a significant difference among the different age and sex groups that were counted during the wet season $(F 2432=630, P<0.05)$. The pairwise comparison of the different age and sex groups through paired $t$ test showed that, the number of adult females was significantly different from the number of adult male $(t=3.76, \mathrm{df}=3, P<0.05)$, sub-adult male $(t=3.96$, df $=3, P<0.05)$, sub-adult female $(t=4.33, \mathrm{df}=3, P<0.05)$, and unidentified sex juveniles $(t=3.91, \mathrm{df}=3, P<0.05)$ in wet season. On the other hand, during dry season, $54.56 \%$ was accounted by adult females while sub-adult males accounted $3.4 \%$ which was the least. The rest $17.2 \%$, $16.14 \%$, and $8.7 \%$ of the population were accounted for juveniles, sub-adult females and adult males, respectively. There was a significant difference among the different age and sex groups counted during the dry season $(F 2468=696.6, P<0.05)$.

Table 2 Habitat use of gelada baboons during wet and dry seasons

\begin{tabular}{lllll}
\hline Seasons & Open grassland & Erica woodland & Plantation forest & Total \\
\hline Wet & 389 & 34 & 12 & 435 \\
Dry & 403 & 56 & 12 & 471 \\
Mean & 396 & 45 & 12 & 453 \\
\hline
\end{tabular}

Table 3 Total number of geladas at different age and sex groups in wet and dry seasons

\begin{tabular}{lll}
\hline Age and sex & Wet & Dry \\
\hline AM & 39 & 41 \\
AF & 238 & 257 \\
SAM & 15 & 16 \\
SAF & 70 & 76 \\
Unidentified juvenile & 73 & 81 \\
Total & 435 & 471 \\
\hline
\end{tabular}

The age and sex ratio of adult male to adult female were the highest during both the wet (1.00:6.1) and the dry (1.00:6.3) seasons in the study area (Table 4).

\section{Group size}

During the wet season, the mean group size of OMU was $17 \pm 1.2$ while that of AMU was $3.75 \pm 1.21$. The band had a mean group size of $79 \pm 1.14$ (Table 5 ).

Furthermore, during the dry season, the mean group size of OMU was $15 \pm 1.18$. AMU was found to be $4 \pm$ 1.2 whereas the band contained a mean group size of $71.5 \pm 1.14$ (Table 6).

\section{Discussion}

In the course of this study, the total number of geladas baboons counted in the study area during the season was 435 while that of the dry season was 471 . There was variation in the total number of geladas counted during wet and dry seasons. Variation in the number of geladas counted in the wet and dry season was also observed in the study of Kassahun and Afework (2017). This variation might be due to the fact that most of the time, the births of young geladas occur after the wet season (Dessalegn and Afework 2014). During the wet season, the farmers cultivate their farmland and chase the gelada baboons to the nearby cliff. Moreover during this season, the climatic condition was somewhat cloudy to properly see the gelada baboons. The above two cases might be the reason for the variation in the number of geladas recorded during the wet and dry seasons.

The age and sex categories were dominated by adult females both during wet and dry seasons. Unequal age and sex ratio was also observed the study of Zewdu et al. (2013). This may be due the reason that sub-adult

Table 4 Age and sex ratio of gelada baboons during wet and dry seasons

\begin{tabular}{llllll}
\hline Season & \multicolumn{4}{l}{ Age and sex ratio } \\
\cline { 2 - 6 } & AM:AF & SAM:SAF & M:F & SAM:AM & SAF:AF \\
\hline Wet & $1.00: 6.1$ & $1.00: 4.67$ & $1.00: 5.7$ & $1.00: 2.6$ & $1.00: 3.4$ \\
Dry & $1.00: 6.3$ & $1.00: 4.75$ & $1.00: 5.8$ & $1.00: 2.56$ & $1.00: 3.38$ \\
\hline AM adult male, $A F$ adult female, SAM subadult male, SAF subadult female
\end{tabular}


Table 5 Mean group size during wet season

\begin{tabular}{llll}
\hline Blocks & OMU size & AMU size & Band size \\
\hline Kundi & 20 & 3 & 58 \\
Arbgebeya & 12 & 3 & 53 \\
Goshber & 16 & 3 & 75 \\
Goshmeda & 20 & 6 & 130 \\
Mean \pm SD & $17 \pm 1.2$ & $3.75 \pm 1.21$ & $79 \pm 1.14$ \\
\hline
\end{tabular}

males are highly sensitive to predation pressure by leopards and dogs. According to Kassahun and Afework (2017), the number of adult females in Debre Libanos was larger than other age and sex categories, and this was closer to the variation observed in the current study area. The ratio of adult males to adult females was 1:6.1 and 1:6.3 in wet and dry seasons, respectively. Adult females also had a ratio of 1:3.3 during the wet season and 1:3.2 during dry season to juveniles. This ratio was almost twice of that was found by Habtamu and Subramanian (2013) in Simien Mountains National Park. During the wet season, the ratio of male to female was 1:5.7 while that of the dry season was 1:5.84. On the other hand, the ratio of adult male to adult female was larger than the ratio of males to females during both seasons. The dry result was similar to the ratio obtained by (Hailu B: Population estimate and structure of gelada baboon (Theropithecus gelada) in Guassa Community Conservation Area, Central Ethiopia, unpublished) in Menz Guassa whereas the wet season result was a little bit opposite. This might be because of the reason that there was one adult male for many adult females due to the OMU group organization of gelada baboons in the study area.

The mean group size of OMU was $17 \pm 1.2$ during the wet season and $15 \pm 1.2$ during the dry season while that of the band was found to be $79 \pm 1.14$ during the wet season and $71.5 \pm 1.14$ during the dry season. This revealed that the mean number of OMU per band was 4.2 and 4.8 in the wet and dry seasons, respectively. During the wet season, the mean group size of AMU was $3.75 \pm$ 1.2 and that of the dry season was $4 \pm 1.2$. In general, the mean group size was smaller than the one observed by (Hailu B: Population estimate and structure of gelada baboon (Theropithecus gelada) in Guassa Community Conservation Area, Central Ethiopia, unpublished) in

Table 6 Mean group size during dry season

\begin{tabular}{llll}
\hline Blocks & OMU size & AMU size & Band size \\
\hline Kundi & 16 & 3 & 54 \\
Arbgebeya & 10 & 3 & 54 \\
Goshber & 16 & 3 & 68 \\
Goshmeda & 18 & 7 & 110 \\
Mean \pm SD & $15 \pm 1.18$ & $4 \pm 1.2$ & $71.5 \pm 1.14$ \\
\hline
\end{tabular}

Menz Guassa which was 18 and 18.4. This might be due to the presence of smaller habitats in the present study area. The mean group size in the present study relatively decreases during dry season which is in contradiction to the result earned by Beehner et al. (2008) in Simien Mountains National Park. The smaller mean group size can be due to lack of food abundance during dry season that results in splitting of the group for foraging. According to Beehner et al. (2008), troop size increases during dry season due to the fact that there will not be spatial restriction. On the contrary, group size increases during wet but decreases during dry season (Ankle-Simons, 2007).

Majority of the gelada baboons were counted from the open grassland habitat type both during the wet and dry seasons. The grasses found in the open grassland habitat type were the best reasons for the geladas to be there. The Erica woodland was the next preferable habitat type both during wet and dry seasons although there were a relatively larger number of geladas during the dry season seen in this habitat. This could be still due to the relatively more availability of food in this habitat than the plantation forest. According to Hunter (2001), geladas spent more time in open plateau habitats in Simien Mountains National Park.

\section{Conclusion}

Wof-Washa Forest could be a good site for eco-tourism as endemic animals and beautiful scenic geography are included in the area. However, the quality of the habitat is getting poorer and poorer due to livestock grazing, agricultural expansion, and invasion of exotic plants like eucalyptus tree. Therefore, the area should be managed with active participation of the local community to ensure sustainable utilization of the resource.

\section{Abbreviations}

AMU: All-male unit; ANOVA: Analysis of variance; OMU: One-male unit

\section{Acknowledgements}

We would like to thank North Shoa Zone Trade Industry and Market Development Department for providing fund to conduct this study.

\section{Funding}

North Shoa Zone Trade Industry and Market Development Department provided fund for data collection.

\section{Availability of data and materials}

The data that supported these results of this research are available from the corresponding author on reasonable request.

\section{Authors' contributions}

BG carried out data collection and MY did the analysis and write up. Both authors read and approved the final manuscript.

Ethics approval

Not applicable

Consent for publication

Not application 


\section{Competing interests}

The authors declare that they have no competing interests.

\section{Publisher's Note}

Springer Nature remains neutral with regard to jurisdictional claims in published maps and institutional affiliations.

\section{Author details}

'Department of Biology, Debre Markos University, P.O.Box 269, Debre Markos, Ethiopia. ${ }^{2}$ Department of Zoological Sciences, Addis Ababa University, P.O.Box 1176, Addis Ababa, Ethiopia.

Received: 5 October 2018 Accepted: 9 December 2018

Published online: 22 December 2018

\section{References}

Ankel-Simons F. Primate anatomy: an introduction. 3rd ed. San Diego: Elsevier Academic Press; 2007.

Beehner JC, Berhanu G, Bergman TJ, Cann MC. Population estimate for gelada (Theropithecus gelada) living in and around the Simien Mountains National Park, Ethiopia. Ethiop J Scie. 2008;3:1-5.

Brnesh $\mathrm{H}$, Tsegaye $\mathrm{G}$, Tadese $\mathrm{H}$, Gelaye $\mathrm{G}$. The status and feeding ecology of Menelik's bushbuck (Tragelaphus scriptus meneliki, Neumann, 1992) in WofWasha forest North Shoa, Ethiopia. Inter J Curr Res. 2015;7:16366-70.

Crook JH. Gelada baboon herd structure and movement: a comparative report. Symp Zool Soc Lond. 1966:18:237-58.

Demel T, Tamrat B. Floristic composition of Wof-Washa natural forest, Central Ethiopia: implications for the conservation of biodiversity. Fed Reper. 1995;106:127-47.

Dessalegn E, Afework B. Diurnal activity patterns and feeding ecology of the endemic geladas (Theropithecus gelada) in the Simien Mountains National Park. Ethiopia Afr J Ecol. 2014. https://doi.org/10.1111/aje.12172.1-7.

Dunbar RIM. The gelada baboon: status and conservation. In: Bourne GH, editor. Primate Conservation. New York: New York Academic Press; 1977. p. 363-85.

Dunbar RIM. The social ecology of gelada baboons. In: Rubenstein, Wrangham RW, editors. Ecological Aspects of Social Evolution. Princeton: Princeton University Press; 1986. p. 332-51.

Dunbar, RIM. The social brain hypothesis. Evol Anthrop. 1998:6(5):178-190.

Eshetu M, Balakrishnan M. Demographic structures of gelada (Theropithecus gelada) in Guassa community protected area, Ethiopia. Glob J Scie Frontr Res: Biol Scie. 2015;15:18-24.

Ethiopian Wildlife and Natural History Society (EWNHS). A Glimse at biodiversity hotspots of Ethiopia: the essential directory for environment and Development; 2010. p. 94

Eyosias W, Teshome S. Allometric equation for biomass determination in Juniperus procera Endl. and Podocarpus falcatus mirb of Wof-Washa forest: implication for climate change mitigation. Amer J Life Scie. 2015;3:190-202.

Habtamu A, Subramanian C. Population size and structure of gelada baboon (Theropithecus gelada -Ruppel, 1835) in Simien Mountains National Park, Ethiopia. Glob J Biol, Agri and Health Scie. 2013;2:102-6.

Hunter CP. Ecological determinants of gelada ranging patterns (Theropithecus gelada). PhD dissertation. Liverpool: The University of Liverpool; 2001.

Iwamoto T. The ecology of Theropithecus gelada. In: Jablonski NG, editor. Theropithecus: the rise and fall of a primate genus. Cambridge: Cambridge University Press; 1993. p. 441-53.

Kassahun A, Afework B. Population estimate, group size and age structure of the gelada baboon (Theropithecus gelada) around Debre Libanos Northwest Shewa Zone, Ethiopia. Glob J Scie Front Res. 2017;17:27-33.

Mori A, Belay G. The distribution of baboon species and a new population of gelada baboons along the Wabi-Shebeli River, Ethiopia. Primates. 1990:31:495-508.

Radek F, Ladislav M, Daria B, Gustav C, Hošek M, Michaela P. The daily pattern of main activities in the gelada baboon (Theropithecus gelada). Acta Univ Agri Silvi Mend Brun. 2014;62:891-6.

Snyder-Mackler N, Beehner JC, Bergman TJ. Defining higher levels in a gelada multilevel society. Inter J Primat. 2012;33:1-15.

Zewdu K, Gurja B, Afework B. Population size, group composition and behavioural ecology of geladas (Theropithecus gelada) and human-gelada conflict in Wonchit Valley, Ethiopia. Pak J Biol Scie. 2013;16:1248-59.

Ready to submit your research? Choose BMC and benefit from:

- fast, convenient online submission

- thorough peer review by experienced researchers in your field

- rapid publication on acceptance

- support for research data, including large and complex data types

- gold Open Access which fosters wider collaboration and increased citations

- maximum visibility for your research: over $100 \mathrm{M}$ website views per year

At BMC, research is always in progress.

Learn more biomedcentral.com/submissions 